\title{
Correction to: Assessing the performance of Canadian credit unions using a three-stage network bootstrap DEA
}

Mohamed Dia ${ }^{1} \cdot$ Pawoumodom M. Takouda ${ }^{1} \cdot$ Amirmohsen Golmohammadi $^{1}$

๑) Springer Science+Business Media, LLC, part of Springer Nature 2020

\section{Correction to: Annals of Operations Research https://doi.org/10.1007/s10479-020-03612-w}

There is a typo in Equation 12 (a "lambda" is missing).

$$
\sum_{j=1}^{n} \lambda_{j}=1
$$

Original article has been updated thus.

Publisher's Note Springer Nature remains neutral with regard to jurisdictional claims in published maps and institutional affiliations.Springer Nature remains neutral with regard to jurisdictional claims in published maps and institutional affiliations.

The original article can be found online at https://doi.org/10.1007/s10479-020-03612-w.

$\triangle \quad$ Mohamed Dia

mdia@laurentian.ca

Pawoumodom M. Takouda

mtakouda@laurentian.ca

Amirmohsen Golmohammadi

agolmohammadi@laurentian.ca

1 Research Centre for Operations and Decision Sciences (RCODS), Department of Finance and Operations, Faculty of Management, Laurentian University, 935 Ramsey Lake Road, Sudbury, ON P3E 2C6, Canada 